\title{
Women's higher health risks in the obesogenic environment: a gender nutrition approach to metabolic dimorphism with predictive, preventive, and personalised medicine
}

\author{
Niva Shapira
}

\begin{abstract}
Women's evolution for nurturing and fat accumulation, which historically yielded health and longevity advantages against scarcity, may now be counteracted by increasing risks in the obesogenic environment, recently shown by narrowing gender health gap. Women's differential metabolism/disease risks, i.e. in fat accumulation/distribution, exemplified during puberty/adolescence, suggest gender dimorphism with obesity outcomes. Women's higher body fat percentage than men, even with equal body mass index, may be a better risk predictor. Differential metabolic responses to weight-reduction diets, with women's lower abdominal fat loss, better response to highprotein vs. high-carbohydrate diets, higher risks with sedentariness vs. exercise benefits, and tendency toward delayed manifestation of central obesity, metabolic syndrome, diabetes, cardiovascular disease, and certain cancers until menopause - but accelerated thereafter-suggest a need for differing metabolic and chronological perspectives for prevention/intervention. These perspectives, including women's differential responses to lifestyle changes, strongly support further research with a gender nutrition emphasis within predictive, preventive, and personalized medicine.
\end{abstract}

Keywords: Women, Gender, Nutrition, Obesity, Metabolic syndrome, Life expectancy, Sexual dimorphism, n-6/n-3 PUFA, Predictive, preventive and personalised medicine (PPPM)

\section{Review}

\section{Introduction}

Women's evolution vs. food scarcity, which necessitated effective fat accumulation for preparing available energy and nutrients for fertility and feeding/caring of offspring, has long translated to a health and longevity advantage. However, this may now be counteracted by the 'obesogenic' environment.

Pubertal gender dichotomy of girls accumulating fat vs. boys losing fat and growing muscles and height $[1,2]$ illustrates an obesity-related aspect of gender differential adaptation to scarcity and women's advantage. However, extreme changes in the environment, particularly increasing food availability/accessibility and reduced mobility, as well as increased calories and reduced nutrient density in

Correspondence: nivnet@inter.net.il

Institute for Nutritional Research, Rabin Medical Center (Beilinson Hospital), Office: 5 Kehilat Zitomir, Tel Aviv 69405, Israel processed foods-together defined as an obesogenic environment-have conferred a great burden of overconsumption and obesity (Figure 1), unrelated to nutritional sufficiency/deficiency [3]. This may be especially critical in females, given their innate tendency toward fat accumulation and risks from nutrient-exhausting pregnancy/lactation, and resultant deficiency disorders [4-6]. This new metabolic 'mismatch' in women could greatly contribute to the recent decline in the gender gap in life expectancy (LE) and in healthy LE (HLE), associated with a slowed increase in female LE and HLE compared to males [7-10] (Figure 2), that is gradually narrowing the gender gap $[11,12]$ resulting from increases in the environmental burden on women's health and consequently on the healthcare system.

Beyond the general perspective that the declining gender LE gap was associated primarily with changes in smoking and alcohol use [14], a new perspective on women's health 


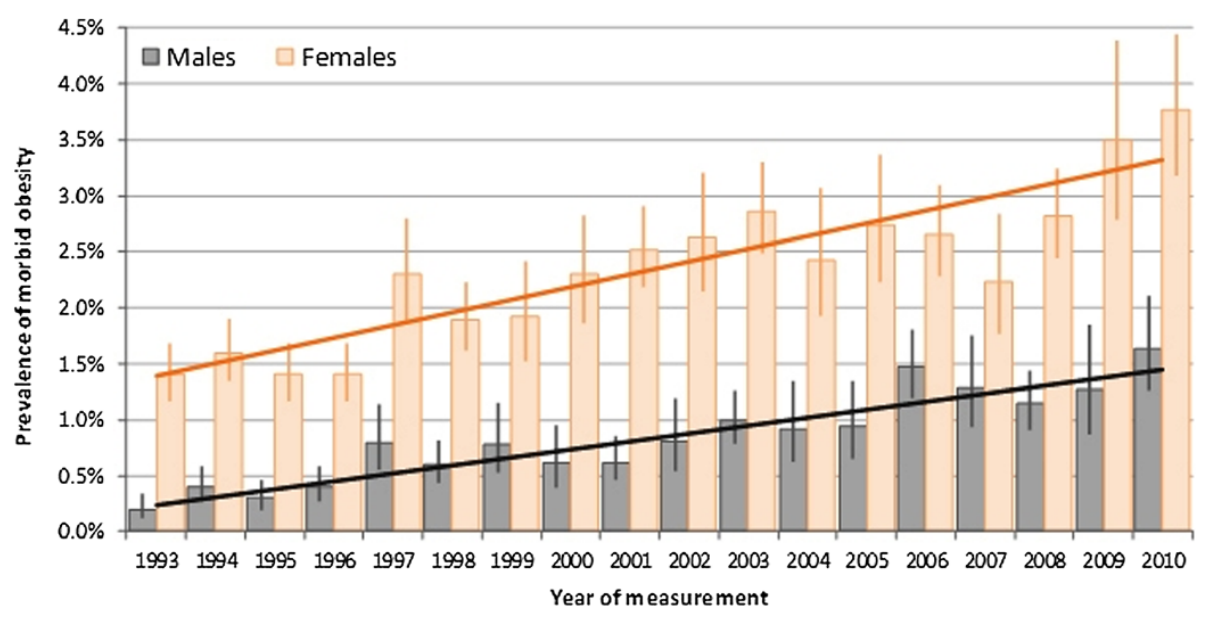

Figure 1 Prevalence of morbid obesity among adults aged 16+ years: Health Survey for England 1993-2010 [13]. The rise of morbid obesity $\left(\geq 40 \mathrm{~kg} / \mathrm{m}^{2}\right)$ has been led by women in developed, high-income countries, i.e. in the UK where between 1993 and 2010 , the prevalence of morbid obesity was consistently higher among women (increasing from 1.5\% in 1993 to 3.8\% in 2010) than among men (increasing from $0.3 \%$ in 1993 to $1.6 \%$ in 2010).

should include their specific metabolic risks and differing timetables, i.e. earlier and higher risk of lifelong obesity, differential fat distribution and risk measures, i.e. body mass index (BMI), waist circumference (WC), and delayed risk manifestation to postmenopausal age, which is associated with reduced estrogen protection. Here, predictive, preventive, personalised nutrition should take a lead- before the risk manifestation-according to the specific timing of physiological events, critical periods, early programming, and their metabolic patterns [15].

The present paper shows women's leading role in the obesity epidemic, which could potentially become their leading lifelong risk factor for disability and mortality. As fewer metabolic studies regarding disease risk have

Gender-environment interaction effect on body fat \% and related health risks (restrictive risks [RR] and obesogenic risks [OR]), and associated trends in gender gaps in life expectancy (LE) and healthy life expectancy (HLE) years ( $\mathrm{F}-\mathrm{M}, \mathrm{F}=$ female, $\mathrm{M}=$ male).

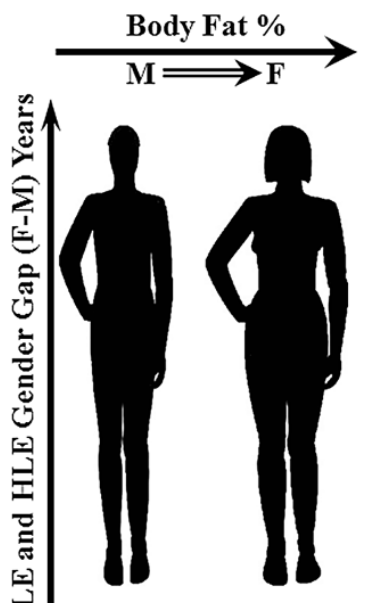

Restrictive

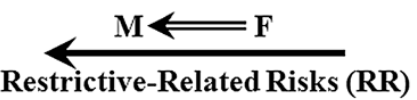

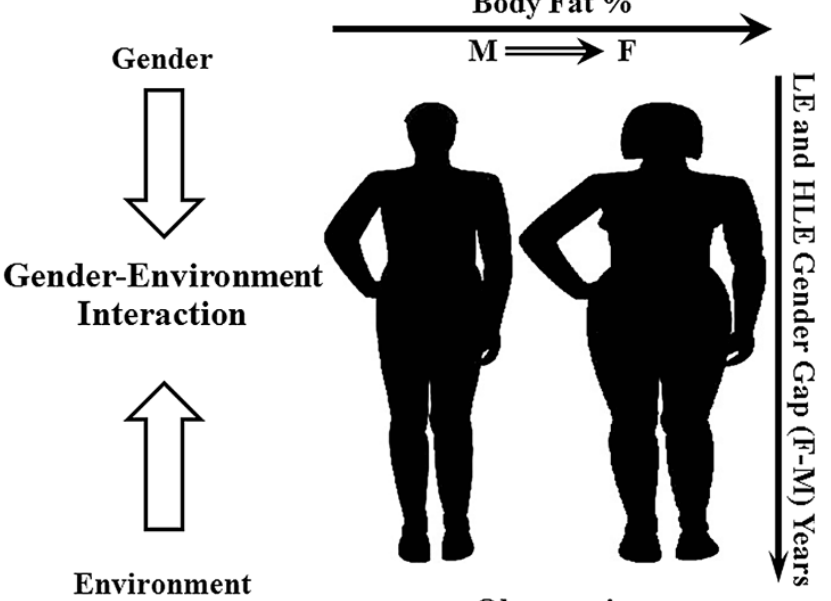

Obesogenic

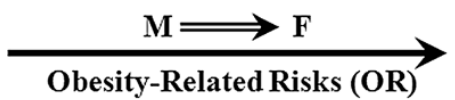

Figure 2 Gender-environment interaction effect on obesity, health risks, life expectancy (LE), and healthy life expectancy (HLE).

Obesogenic (increased calories and reduced mobility) conditions in Western lifestyles, compared to historically restrictive dietary conditions and high mobility, have conferred a great burden of overconsumption and obesity. Women's innate tendency toward fat accumulation and higher lifelong body fat percentage could make them more vulnerable and have contributed to the recent decline in the gender gap (females-males, years) of life expectancy (LE) and healthy LE (HLE) years. 
previously been conducted in females, there is a great need for better understanding of women's specific nutritional risks resulting from environmental changes. Approaching metabolic dimorphism as a major factor in gender nutrition is now becoming crucial for designing and enhancing healthcare quality and effectiveness of personalised medicine [16], as comprehensively described in the recent White Paper of the European Association for Predictive, Preventive and Personalised Medicine [17].

\section{Women's declining advantage in health and life \\ expectancy}

Though women still outlive men throughout the world, their LE advantage seen in the early twentieth century is now declining, especially in Western countries [11,12]. For example, in France, previously a gender gap leader (7.66 years), the LE gap stopped increasing in the 1980s and began decreasing in recent years, which was partially attributed to a reduction in cardiovascular disease (CVD) and lung cancer mortality in men, as found in a few European countries [18]. In Norway during the last 25 years, the LE increased by $\approx 6$ years in men and only $\approx 3$ years in women, resulting in a 2.5-year reduction in gender LE gap [7]. In the UK, between 1990 and 2002, the average annual rate of improvement in mortality was $\approx 30 \%$ higher in men than in women [8]. Similar trends had previously been observed in the USA, Sweden, England and Wales, Hungary, Sweden, Australia [19], and Canada [20], though not seen in Japan [21].

Whereas healthy LE has declined in women more than in men, i.e. between 1989 and 2000 by 4.3 years vs. 0.8 years, respectively [18], their unhealthy LE has increased, i.e. women with heart disease have greater LE at 50 years than men, 7.9 vs. 6.7 years, though women's heart disease onset tends to be delayed by $\approx 3.0$ years and heart attacks by 4.4 years compared to men [22]. Similarly, HLE in Italian women was reduced by 2 years compared to their previous advantage, with resultant equal LE at age 65 of $\approx 7$ years, for both genders [9].

A gender health-survival paradox of women's higher morbidity rates despite longer LE-as found in Western countries-is also found in Singapore, where at age 65, women's remaining life yields more disabilities, such as hypertension, bone/joint problems, walking difficulties, and visual and functional impairments compared to same-aged men [10]. The above and further population studies show that women's HLE is compromised beyond their declining longevity, which may necessitate specific preventive strategies.

\section{Obesity-related decreased life expectancy and increased disability}

Many studies have demonstrated that obese individuals suffer an elevated risk of death [23] and that a high level of obesity is contributing to reduced LE, i.e. in the USA, LE is falling below that of most other industrialised countries, with a ranking of 32nd in the world in 2008 [24], concurrent with the highest per capita expenditure on healthcare in the world [25]. Obesity was associated with reduced US LE at age 50 years by 1.54 and 1.85 years for women and men, respectively, a shortfall (by $42 \%$ and $67 \%$ ) relative to countries with higher LEs, and a higher (by 25\% and 40\%) effect on LE than in Canada and the UK, the two countries with the next-highest rates of obesity [26]. Excess US BMI was responsible for approximately 95 million years of life lost (YLL), with women accounting for more than twothirds [27], and their obesity-associated reduction in longevity was higher than that in other countries [28], possibly because of younger age and higher severity of obesity. Of note, an increase in two BMI units in overweight populations was estimated to decrease lifespan, i.e. in men by 1 year, comparable to a $10 \%$ increase in the prevalence of smoking $[27,29]$.

Beyond the effect of obesity (BMI of $30-34.9 \mathrm{~kg} / \mathrm{m} 2$ ) on reducing $\mathrm{LE}$, it was also shown to reduce disability-free $\mathrm{LE}$ [30], i.e. among men by 2.7 years, concurrent with increasing LE with disability by 2.0 years, compared to changes among women by 3.6 years and 3.2 years, respectively, and overweight (BMI 25-29.9) increased LE with disability for women only, by 2.1 years. Women's longest HLE was shown at BMI of 18.5-22.9, men's at 25-29.9 (Figure 3) and decreased thereafter, together with increasing LE with disabilities [31].

\section{Women's lead in the obesity epidemic}

Worldwide obesity has more than doubled since the 1980s, and rates continue to push upward throughout the world. By 2008, an estimated 1.46 billion adults and 170 million children worldwide were overweight (BMI $\geq 25 \mathrm{~kg} / \mathrm{m}^{2}$ ) or obese (BMI $\geq 30$ ), with higher rates in women, though varying widely by country. For example, an estimated $18 \%$ of women in France are obese, in Greece 26\%, in Mexico 35\%, and in Saudi Arabia 44\%; in contrast, the percentage in both Japan and China was $3 \%$ [32]. In the USA, with an overall prevalence of $68.3 \%$ overweight [28] and 33.9\% obesity, women show higher rates than men of severe obesity (BMI $\geq 35,17.8 \%$ vs. $10.7 \%$ ) and morbid obesity (BMI $\geq 40,7.2 \%$ vs. $4.2 \%$ ) differences of $78 \%$ and $71.4 \%$, respectively [33].

However, longitudinal trends previously showing women's increased obesity prevalence-that initially preceded men's-later slowed, leading to a decline in the gender gap, with women's prevalence over the last 12 year period increasing by only $6.3 \%$ vs. men's by $17.1 \%$ (1999-2008) [28].

\section{Women's body fat percentage vs. BMI as risk-predictive} Though the definition of obesity is uniform for women and men, women typically have higher body fat percentage 

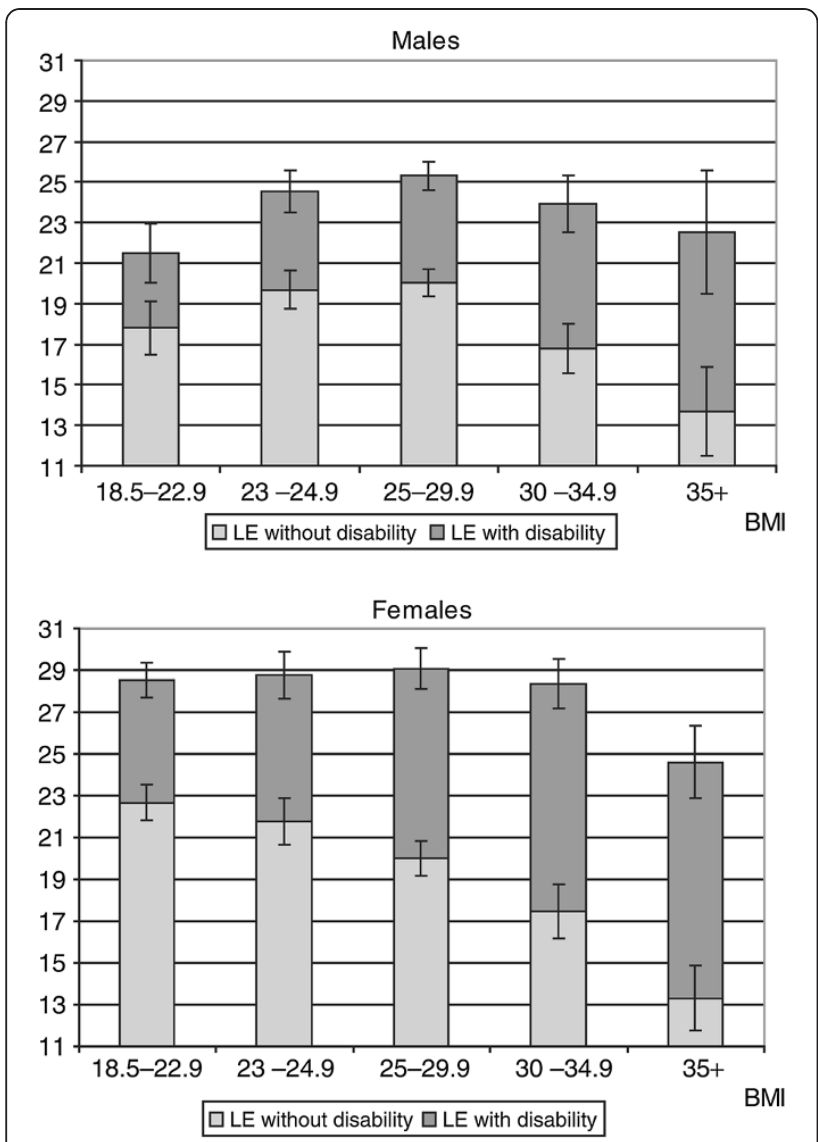

Figure 3 Life expectancy at age 55 with/without disability in activities of daily living (univariate analysis). Error bars represent 95\% confidence intervals of disability-free and total life expectancy [31]. The average LE at 55 years of age is 24.0 years for men and 28.2 years for women (excluding underweight individuals). The longest disability-free LE was found with a BMI between 18.5 and 22.9 for women and 25.0 and 29.9 for men. Mild obesity (BMI 30-34.9) did not shorten total LE, but at age 55, it shortened disability-free life to 2.9 years for males and 4.3 years for females compared to high normal weight (BMI 23-24.9). Severely obese men live an average of 6.0 years less free from $A D L$ disability and women for 8.4 less years. For men, low normal weight (BMI 18.5-22.9) lowers both total and disability-free LE.

and lower fat-free mass (FFM) for the same BMI cut-off point [34]. In NHANES III, women's average body fat percentage, at $20-80$ years, was higher than men's by $44 \%$ ( $34.9 \%$ vs. $24.3 \%$, respectively), despite similar corresponding BMIs (26.27 vs. 26.83). Thus, women's BMI may not accurately reflect but rather may partially mask their actual obesity [34]. This may lead women to a condition of 'metabolically obese/normal weight'-already at a young age-wherein despite having a normal BMI, they display body composition and metabolic characteristics that may predispose them to development of metabolic syndrome (MetS) [35].

Women's tendency toward obesity compared to men's is manifested by several metabolic patterns, including lower fat oxidation, especially postprandially, with more efficient fat storage [36]; lower resting energy expenditure rates [37-39]; higher response to insulin (as shown in glucose metabolism in both the liver and muscle) and to an exercise with weight loss diet combination [40]; higher adipose tissue-expanding capacity with long-term high-fat feeding [41]; and higher leptin levels, associated with higher inflammatory (C-reactive protein [CRP] and MetS risk, that were independent of adiposity [42].

In metabolically obese normal-weight women, there is a tendency toward greater central fat mass, associated with reduced insulin sensitivity $[43,44]$, shown even with normal glucose tolerance [45]. Further, they may have smaller particles of low-density lipoprotein (LDL); higher concentrations of oxidised LDL, TNF-alpha, interleukin (IL)-6, and leptin; and lower plasma adiponectin than women with normal visceral adiposity [46], all of which contribute to increased obesity-related disease risk. Such hidden obesity was found in underactive Western women and in Asian women, who were observed to have a higher body fat percentage for each BMI level, potentially associated with prominent abdominal obesity, higher intramuscular and liver fat content, and predisposition to insulin resistance and diabetes mellitus [47].

According to body fat percentage, the prevalence of 'at risk' (preobese or obese) among normal BMI men and women was $69 \%$ and $85 \%$, respectively, suggesting that screening for adiposity in individuals with a normal BMI could further identify those at higher risk for cardiometabolic disturbances and cardiovascular mortality, especially among women, as the false-negative classification of BMI was stronger for women than for men [48]. Together, the above places women at risk for greater obesity and sequelae, especially with increasing exposure to the global obesogenic environment.

\section{Women's earlier and greater predisposition to obesity}

Women's obesity tendencies begin much earlier than men's, already in the womb [49]. Girls aged $\leq 10$ years have $28 \%$ greater total fat and $30 \%$ more subcutaneous fat than boys, with similar amounts of visceral fat [1]. Dimorphism in total fat mass and in fat tissue distribution (visceral vs. subcutaneous) progresses from prepuberty [50], where body fat percentage declines in boys as they gain muscle, but increases in girls [2]; correspondingly, early-maturing boys are thinner, whereas early-maturing girls are fatter [51], and menarche seems to occur most frequently with $\geq 17 \%$ body fat [52]. Further, adult women's age of increasing obesity is much earlier than men's, rates higher at 20-39 years of age by $23.7 \%$ for $\mathrm{BMI} \geq 30$ and $100 \%$ for $\mathrm{BMI} \geq 35$ and at $40-59$ years by $11.4 \%$ and $68.1 \%$, respectively [28].

These epidemiological trends and gender differences underscore the importance of defining sex-specific characteristics and women's earlier and stricter prevention 
and management of obesity and related risks, such as MetS, diabetes mellitus, coronary heart disease (CHD), and cancer [53].

\section{Women's delayed risk manifestation: hormonal schedule vs. obesity pressure}

Estrogen and estrogen receptors (ER) are well-known regulators of several aspects of metabolism, including glucose and lipid metabolism, and impaired estrogen signalling is associated with the development of metabolic diseases. Here, ER $\alpha$ seems to play a protective role in insulin and glucose metabolism, through effects on the liver, adipose tissue, muscle, and pancreatic $\beta$ cells and on central regulation of food intake and energy expenditures. ER $\beta$, on the other hand, has the potential to negatively influence insulin and glucose metabolism by impairment of adipose tissue function, probably through augmented PPAR $\gamma$ signalling, and declined expression of GLUT4 in the muscle [54]. Several epidemiological and prospective studies have linked estrogen and the ER to various aspects of metabolic disease and to estrogen protection in premenopausal women.

The onset of menopause dramatically increases the risk for women to develop disease states coupled to the MetS, such as obesity, CVD, and type 2 diabetes. Here, estrogen deficiency is strongly linked to the development of insulin resistance and subsequent manifestations in various metabolic tissues (Figure 4) that could be repaired by hormone replacement therapy [54]. For example, estrogen's inverse relation with energy intake, as shown with hormonal shifts during the menstruation/ovulation cycle [52], may partially contribute to young women's ability to control their weight vs. increasing tendency toward obesity with menopause. Similarly, premenopausal women's capacity for removal of very-low-density lipoprotein (VLDL) cholesterol from the plasma is greater compared to men's and to menopausal women's, with resultant rise in the latter's plasma lipoproteins and associated disease risk [55].

However, with increasing obesity levels in young women, MetS and related risks may be manifested earlier in this age group, suggesting that weight gain at an early age predisposes young women to risks as seen with menopausal obesity, due to their earlier and higher rates of obesity-related accumulation of metabolic risks than in men [56].

\section{Women-specific chronological perspectives on health risk}

Whereas women were previously considered at high CVD risk if their 10-year predicted risk of CHD was more than $20 \%$, their cumulative lifetime risk may be underestimated because of delayed manifestation to postmenopausal age. This may be related to the peak tendency toward weight gain occurring around 50 years of age [57], associated with higher rates of gain [58],

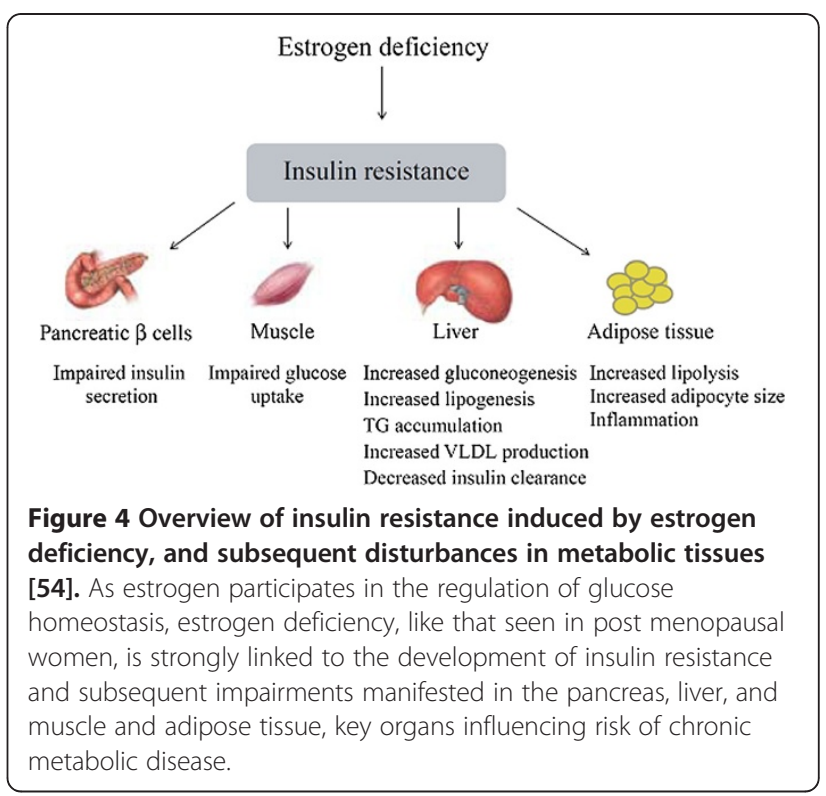

difficulty maintaining body weight [59], and tendency toward weight regain following weight loss diets, which is highly predictive of later risk [60]. Updated guidelines from the American Heart Association note that newer risk formulas are available to predict 10- and 30-year risks for all CVD events, including CHD, stroke, and heart failure; for example, the 10-year predicted risk for CHD of $>20 \%$ now includes women aged $>60$ years with elevated CRP as candidates for medication intervention, even if they do not have heart disease or elevated lipid levels. Other inflammatory/oxidative medical conditions, such as rheumatoid arthritis, systemic lupus, and a history of pre-eclampsia, gestational diabetes, or pregnancyinduced hypertension, have also been added to the at-risk category. Such additional new high-risk criteria for CVD in women suggest a differential definition of womenspecific recommendations for lifestyle and healthcare according to the long-term effectiveness-based paradigm, beyond the evidence-based approach to immediate risk measures [61].

\section{Women-specific healthy lifestyle aspects}

Apart from smoking and/or exposure to environmental ('second-hand') tobacco smoke and alcohol, obesitythe suggested leading cause of decreasing gender gap in LE [14] - is associated with most of women's risk factors for MetS and related chronic diseases, i.e. excess body weight/obesity (BMI $\geq 25$ ), waist circumference (WC $\geq 35$ in. or $>88 \mathrm{~cm}$ ), with elevated blood pressure $(\geq 120 / 80 \mathrm{mmHg}$ ), dyslipidaemia (LDL cholesterol $\geq 100$ $\mathrm{mg} / \mathrm{dL}$, high-density lipoprotein (HDL) cholesterol $<50$ $\mathrm{mg} / \mathrm{dL}$, triglycerides $(\mathrm{TG}) \geq 150 \mathrm{mg} / \mathrm{dL}$, and non-HDL cholesterol $\geq 130 \mathrm{mg} / \mathrm{dL}$ ) [61], and dysglycaemia [62]. Long-accepted exacerbating factors remain as they were: 
inadequate physical activity (i.e. $<75-150 \mathrm{~min} /$ week of moderate-vigorous exercise with an aerobic element) and dietary factors, including low intake of fruits and vegetables, whole-grain/high-fibre foods, and $n-3$ polyunsaturated fatty acid (PUFA; i.e. from $n-3$ PUFA-rich fish $^{\mathrm{a}}$ or from supplements), with high intake of saturated fatty acid (SFA), cholesterol, alcohol, sodium, sugar, and trans-FA ( $t$ FA) [61]. Low socioeconomic/cultural status is another risk factor highly associated with increased obesity, especially in women-found to be key in a recent re-evaluation of the United States Mortality File [63] - and in low- and medium-developed countries [64], requiring specific considerations and economic and cultural approaches that are beyond the scope of this manuscript.

Healthy lifestyle in women that was associated with a significantly reduced risk of total and ischaemic stroke [65] consisted of no smoking, low BMI $(\leq 22)$, moderate alcohol consumption (4-10.5 drinks per week ${ }^{\mathrm{b}}$ ), regular exercise (more than four times per week), and a healthy diet, incorporating high fibre, folate, and $n-3$ PUFA, with generally high PUFA/SFA ratio, and low $t$ FA and glycaemic load (GL). Adherence to these lifestyle guidelines could dramatically reduce the risk of CHD by approximately $82 \%$ [66]. Additionally, adherence to the American Cancer Society's prevention guidelines-including for BMI, physical activity, diet, and alcohol consumptionlowered the risk of cancer and all-cause mortality in nonsmokers [67]. Further detailed recommendations for primary prevention included adjusted intake of meats and fatty foods-especially sources of $n-6$ and $n-3$ PUFA - adding olive oil, selected vegetables, and citrus fruits, and adequate body fat/lean mass proportions [68]. A dietary pattern high in fruit and low-fat dairy and low in white bread, processed meat, margarine, and soft drinks was suggested to help prevent abdominal fat accumulation [69]. The above suggests that major Western diseases share a common metabolic-nutritional basis and thus require similar preventive measures. However, the alcohol link to cancer risk [70-72] vs. benefits to heart health and diabetes [73] is a reminder that the specificity of foods and risk factors should not be overlooked, especially with regard to the gender aspect $[70,71,74,75]$. The Mediterranean diet that has repeatedly demonstrated an advantage against Western diseases and was further suggested as a nutritional framework for the predictive, preventive, and personalised medicine (PPPM) approach [76] can be effectively adapted and applied to various metabolic states, including those associated with gender-specific risks.

\section{Women-specific aspects of weight management}

The general combination of reduced calorie diets and exercise (both aerobic and resistance) [77] was repeatedly confirmed in both sexes to be effective in muscle preservation, preferential reduction of abdominal vs. subcutaneous adipose tissue, and improvement in fitness capacity compared to diet alone [78]. However, such a combination, which was further associated with a twofold greater improvement in insulin action compared with diet alone in men [79], did not show similar effectiveness in women [80], in whom exercise alone, even without caloric restriction and/or weight loss, was associated with reduced total and abdominal obesity and insulin resistance [81].

Women's fat loss, primarily subcutaneous vs. intraabdominal in men, yields much smaller improvements in their specific risk factors, such as TG and HDL cholesterol levels, compared to men losing the same amount of weight/fat, but mostly abdominal [82]. Though WC is known to be positively associated with diabetes in both sexes, increasing WC was more closely associated with diabetes in women than in men [83], which may suggest higher sensitivity of WC as a metabolic measure in women. The above suggests women's need for specific metabolic emphases in obesity management, beyond BMI and weight loss diet per se, vs. their specific risks and chronological aspects compared to men's achieving better risk reduction already through weight loss and dietary restriction [84].

\section{Dietary macronutrients and metabolic aspects}

Fats A low-fat/cholesterol diet is routinely recommended for individuals with elevated plasma LDL cholesterol concentrations [85], though the combination of a weight loss diet with exercise was less effective in improving lipoprotein levels and LDL size in women than in men [86]. A diet low in fat (25\% kcal), SFA (7\%), and cholesterol (100 mg/day) - consistent with the NCEP Step II diet-only partially attenuated the increase in LDL cholesterol during menopause onset [87]. A diet low in fat and high in vegetables, fruit, and whole grains in the Women's Health Initiative study showed women to have a smaller decrease in plasma lipoprotein levels, similar decreases in particle sizes of LDL and HDL, but greater reductions in postprandial TG levels compared to men [85]. As increasing carbohydrate intake may increase women's risk more than men's [88], a low-fat diet with carbohydrate substitution may not necessarily provide women with the metabolic protection against obesity-related risk that has been shown in men. These findings may suggest a need for gender-based dietary interventions to improve specific risk factors, with awareness of women's differential response to strategies that have successfully been targeted toward men [89].

Fatty acids Both essential fatty acids (EFA), linoleic acid (LA; 18:2n-6) and alpha-linolenic acid (ALA; 18:3n-3), are known for their lipidemic advantages, i.e. for 
reducing LDL cholesterol and TG. Substitution for SFA with $n-6$ PUFA has demonstrated an advantage in reducing LDL/HDL and TC/HDL ratios and TG levels, thus improving metabolic factors and related effects in both men and women. However, the unsaturated character of PUFA may be associated with greater lipid and LDL oxidation, especially with inflammation, i.e. facilitated by high $n-6$ proinflammatory eicosanoids, believed to play a key role in chronic diseases and accelerated ageing in conditions of a high- $n-6$ Western diet $[90,91]$. Essential PUFA are further converted in the liver to LCPUFA, LA into arachidonic acid (20:4 n-6), and ALA into eicosapentaenoic acid (20:5 n-3) and docosahexaenoic acid $(22: 6 n-3)$. Their conversion varies according to gender and age, being highest in young women-especially during pregnancy $[92,93]$-compared to males $[94,95]$ and declining with age along with levels of the rate-limiting enzymes delta-5- and delta-6-desaturases, more in women than in men [96]. Desaturase activity is reduced with high SFA intakes [97] and cholesterol [98] and increased with a high- $n-3$ PUFA and/or MUFA diet [97]. LA (n-6) and ALA (n-3) share and compete for ratelimiting conversion enzymes, emphasizing the importance of the $n-6 / n-3$ PUFA ratio for health and sex-related differential predisposition. Women's higher production of eicosanoids from either dietary $n-6$ or $n-3$ PUFA, which are pro- and/or anti-inflammation/coagulation/carcinogenesis, respectively, yields stronger implications for differential CVD and cancer pathophysiology and clinical outcomes, corresponding to their dietary PUFA ratios, as compared to men's.

An ' $n-6$ Gender Paradox' hypothesis' was proposed, based on the Israeli case study of women's higher risk with $n-6$ PUFA vs. men's benefit. Here, women's worse health ranking vs. men's relative advantage in conditions of high dietary $n-6$ PUFA (10-12\% kcal) [99] led to the unexpected observation of low national health status, previously defined as the 'Israeli Paradox' [100,101]. The above suggests that with the same diet, at certain high levels of $n-6$ PUFA, women's greater transformation to eicosanoids with proinflammatory, carcinogenic, aggregatory characteristics may put them at greater risk compared to men, who may benefit due to lower EFA transformative capacity. In a recent Danish epidemiological study, an $n-6$ PUFA increase was associated with weight gain and increased WC in women, while the opposite was shown in men [102], which could further support a differential response and high- $n-6$ risk for women vs. men's advantage.

Carbohydrates and glycaemic effects High carbohydrate intake may be associated with a disadvantage for the lipid profile, including high TG and VLDL, especially in overweight postmenopausal women [103], reflecting the high impact of insulin on their lipid metabolism [38]. Concurrent decreased LDL particle size further explains the link between high dietary carbohydrates and women's CVD risk [104].

While in men replacing SFA with carbohydrate from grains, vegetables, legumes, and fruit effectively reduced total and LDL cholesterol blood levels [87], only a moderate reduction was observed in women, with lesser effects on CVD [89]. Replacement of SFA by carbohydrates, especially refined sources and 'added sugars', increases plasma TG and small LDL particles and reduces HDL, which are of particular concern in the context of the increased prevalence of obesity and insulin resistance, all especially critical for women [88].

In the EPICOR study, women in the highest quartiles of carbohydrate intake, GI, and GL had a significantly greater risk of CHD (by about twofold) than those in the lowest quartile, while a lesser association was found in men [88]. A twofold increased CHD risk with high GL, most evident among women with $\mathrm{BMI} \geq 23$, was found in follow-up research over a 10-year period (729,472 person-years), but not among normal-weight women [105]. Dietary GI and GL were progressively associated with CHD in various populations [106] and with plasma CRP levels, in general and in healthy middle-aged women [107], suggesting an explanatory link between women's ischaemic heart disease with overweight and their susceptibility to insulin resistance [108].

Proteins Although energy restriction alone often leads to weight loss, the composition of the lost tissue also matters, and high loss of lean mass could have deleterious metabolic consequences. This is especially critical for women with innately low initial FFM, a tendency toward a plateau in weight loss, and for later weight regain [56,109]. Moreover, because skeletal muscles play roles in energy metabolism, their potential loss in the weight reduction process emphasises the need to focus on the composition of the lost weight for preservation of lean tissue, rather than relating merely to scale weight. Here, higher protein, lower carbohydrate, and GI energyrestricted diets have been shown to help offset women's lean mass loss, especially when associated with resistance exercise [110].

A high-protein diet was more effective for women, who lost nearly twofold more total and abdominal fat compared with women on the low-protein diet, whereas in men, there was a lesser difference in fat loss between diets; in both sexes, a high-protein diet caused greater total and LDL cholesterol reductions $[111,112]$, with no effect on blood TG [112]. A high-protein ( $\geq 40 \% \mathrm{kcal})$ diet was also more effective in women with polycystic ovary syndrome, yielding a greater reduction in body weight, body fat, WC, and blood glucose than the 
standard protein $(15 \% \mathrm{kcal})$ diet after 6 months [113]. A high-protein diet (1:1 vs. 3:1 carbohydrate/protein ratios) was superior to a low-fat and high-carbohydrate diet, with or without an aerobic/resistance training programme, for effective weight loss, nitrogen balance, improved body composition, and reduced risk factors for the MetS in overweight and obese women [114]. A high-protein, highdairy, energy-restricted diet plus exercise combination was further linked to improved energy-protein balance compared to a lower dairy, higher protein diet, as shown by greater losses of total and visceral fat, smaller losses of lean mass, and increases in body strength despite identical weight loss [110]. Moreover, during adolescence, higher dairy product intake was associated with a lower risk of later adult type 2 diabetes, partially explained by the persistence of the consumption pattern through adulthood and results of a cumulative high-protein, high-dairy effect [115]. A high-protein, low-carbohydrate diet was also found to reduce blood glucose, insulin, and lactate levels and to prevent cancer initiation and to slow tumour growth [113].

\section{Physical activity}

Sedentary life, a characteristic of the modern environment, is a known health risk factor. Moreover, increased sitting time was recently found to be an active and independent risk factor, positively associated with fasting insulin, leptin, leptin/adiponectin ratio, CRP, and IL-6 in women, more than in men. These associations remained significant after additional adjustment for total moderate- to vigorousintensity physical activity [116]. In contrast, physical activity was inversely correlated with BMI, insulin levels, CRP, leptin, WC, and body fat percentage in young and middleaged women, suggesting 'anti-age'-related increases in the above measures with physical activity that may potentially counteract sedentariness and age effects in women [117]. Additionally, non-exercise activity, all activity that is not sleeping, eating, or sports-like exercise, could be a critical component for increasing energy expenditure and metabolic rate, maintaining FFM, and preventing weight gain, obesity, and sedentariness-related risk [81].

As women oxidise proportionately more lipids and less carbohydrates and protein compared to men, and as they do not build muscle glycogen with a carbohydrate load but rather more body fat, their exercise-related fat loss is critical for improved body composition $[116,118]$. Exercise-associated increases in lipolysis in abdominal visceral fat and reduction of their related risks, despite a lower response from luteal-femoral adipose tissue, explains the higher exercise-related benefit and reduction in women's morbidity and mortality, independent of BMI or weight loss, compared to men [119].

A combined exercise and weight loss diet was associated with the greatest reduction in women's total, abdominal, and subcutaneous fat; reduced insulin resistance $(\approx 32 \%)$ in the exercise plus diet group, but not with diet alone; and WC closely reflecting the benefits of reducing abdominal obesity, whereas BMI alone may mask the positive effects of exercise [81]. The correlation between recreational physical activity and reduction in risk of breast cancer recurrence and mortality, which are known to be associated with increased abdominal obesity, further support the special importance of physical activity to women [120].

\section{Conclusions}

Findings showing women's differential metabolic responses have suggested a gender effect on biochemicalendocrinological patterns, metabolic mechanisms, and risk factors, emphasising the importance of more gender-specific prevention strategies. This is especially relevant vs. environmental changes and the obesogenic epidemic, with women's lead in earlier and higher obesity rates and related disease risk, though with manifestation mostly delayed to menopausal age.

Women's differential metabolic responses compared to men throughout the life cycle strongly suggest a need for gender-specific strategies against obesity and chronic diseases such as CVD, diabetes, MetS, and cancer, including differential metabolic biomarkers and chronological patterns across the spectrum of diseases. This is especially relevant in light of women's unique vulnerability to modern environmental pressures, including increased sedentary lifestyle, obesity, glycaemic load, dietary $n-6 / n-3$ PUFA ratio, and transitional socioeconomic and psychosocial stresses. Applying men's knowledge to women's practice may not only yield lower benefits, but may also further enable exacerbation of metabolic imbalance, i.e. substituting dietary fat with carbohydrates and/or repeated weight loss diets without considering the preservation of women's lean body mass, which may gradually reduce their metabolic balance and resistance to Western diseases, despite greater benefits for men. Further, the differential response to higher protein/carbohydrate ratios, to low glycaemic load, as well as to exercise vs. sedentary lifestyle should be considered for differential prevention and intervention strategies. A differential time perspective is also required, considering females' much earlier fat accumulation process, which presets the metabolic patterns for later increases in obesity risks compared to males. Even a measure considered basic, i.e. BMI, may underestimate the female obesity state and rather masks fat percentage, which could better reflect the metabolic obesity state, which is more closely associated with obesity risk, especially with android type, manifested by abdominal subcutaneous and visceral fat and high WC.

As CVD prevention shares recommendations with those of cancer as well as other chronic Western diseases, 
women's approach may be better based on their specific metabolic risks, biomarkers, and chronological patterns across the spectrum of conditions, beyond specific diagnosis, prevention, and intervention. Much epidemiological study and clinical research are needed, including interventional trials for attaining women-specific understanding of metabolic risks and epidemiological evidence-based recommendations for designing targeted nutritional strategies within the context of gender nutrition and the PPPM approach to health- care.

\section{Endnotes}

${ }^{a}$ Pregnant women are generally counselled to avoid eating types of fish with the potential for the highest level of mercury contamination (i.e. shark, swordfish, king mackerel, or tile fish).

b The American Cancer Society's recommendation for alcohol intake was recently reduced to no more than one drink per day for women and two for men [121], in response to findings of alcohol-cancer links [74] even with intake previously considered 'low' [61,70,71,74,75].

\begin{abstract}
Abbreviations
ALA: Alpha-linolenic acid; BMI: Body mass index; CHD: Coronary heart disease; CRP: C-reactive protein; CVD: Cardiovascular disease; EFA: Essential fatty acid; ER: Estrogen receptor; FA: Fatty acid; FFM: Fat-free mass; Gl: Glycaemic index; GL: Glycaemic load; HDL: High-density lipoprotein cholesterol; HLE: Healthy life expectancy; LA: Linoleic acid; LCPUFA: Longchain polyunsaturated fatty acid; LDL: Low-density lipoprotein cholesterol; LE: Life expectancy; MetS: mMetabolic syndrome; MUFA: Monounsaturated fatty acid; $n-:$ Omega (-3, $-6,-9$ unsaturated fatty acids); NCEP: National Cholesterol Education Project; NHANES: National Health and Nutrition Examination Survey; PPPM: Predictive, Preventive, and Personalised Medicine; PUFA: Polyunsaturated fatty acid; SFA: Saturated fatty acid; tFA: Trans-fatty acid; TG: Triglycerides; TNF: Tumour necrosis factor; VLDL: Very-low-density lipoprotein cholesterol; WC: Waist circumference.
\end{abstract}

\section{Competing interests}

The author declares that she has no competing interests.

\section{Acknowledgements}

The author thanks Ossie Sharon, M.S., R.D., and Hagit Hershkowitz-Friedman, M.Sc., for their greatly appreciated assistance in the preparation of this manuscript.

Received: 27 September 2012 Accepted: 13 December 2012

Published: 12 January 2013

\section{References}

1. Arfai K, Pitukcheewanont PD, Goran MI, Tavare CJ, Heller L, Gilsanz V: Bone, muscle, and fat: sex-related differences in prepubertal children. Radiology 2002, 224:338-344

2. Veldhuis JD, Roemmich JN, Richmond EJ, Rogol AD, Lovejoy JC, SheffieldMoore M, Mauras N, Bowers CY: Endocrine control of body composition in infancy, childhood, and puberty. Endocr Rev 2005, 26:114-146.

3. Laraia BA, Bodnar LM, Siega-Riz AM: Pregravid body mass index is negatively associated with diet quality during pregnancy. Public Health Nutr 2007, 10:920-926.

4. Makrides M, Gibson RA: Long-chain polyunsaturated fatty acid requirements during pregnancy and lactation. Am J Clin Nutr 2000, 71:307S-311S.

5. Prentice A, Jarjou LM, Drury PJ, Dewit O, Crawford MA: Breast-milk fatty acids of rural Gambian mothers: effects of diet and maternal parity. J Pediatr Gastroenterol Nutr 1989, 8:486-490.

6. Muller $\mathrm{O}$, Krawinkel M: Malnutrition and health in developing countries. CMAJ 2005, 173:279-286.
7. Statistics Norway: Population Statistics. Deaths 2010. The Gender Gap Decreases. Oslo: Statistics Norway; 2011.

8. Howse K: Increasing Life Expectancy and the Compression of Morbidity: A Critical Review of the Debate: Working Paper No. 206. Oxford: Oxford Institute of Ageing, University of Oxford; 2006.

9. Gennaro V, Ghirga G, Corradi L: In Italy, healthy life expectancy drop dramatically: from 2004 to 2008 there was a 10 years drop among newborn girls. Ital J Pediatr 2012, 38:19.

10. Yong $V$, Saito $Y$, Chan A: Gender differences in health and health expectancies of older adults in Singapore: an examination of diseases, impairments, and functional disabilities. J Cross Cult Gerontol 2011, 26:189-203.

11. Trovato F, Lalu NM: Narrowing sex differentials in life expectancy in the industrialized world: early 1970's to early 1990's. Soc Biol 1996, 43:20-37.

12. Trovato F, Heyen NB: A varied pattern of change of the sex differential in survival in the G7 countries. J Biosoc Sci 2006, 38:391-401.

13. National Obesity Observatory (NOO): Morbid Obesity. Oxford: NOO; 2010.

14. McCartney G, Mahmood L, Leyland AH, Batty GD, Hunt K: Contribution of smoking-related and alcohol-related deaths to the gender gap in mortality: evidence from 30 European countries. Tob Control 2011, 20:166-168.

15. Shapira N: A gender-specific nutritional approach to women's healthcare. In Healthcare Overview: New Perspectives. Edited by Costigliola V. Dordrecht: Springer; 2012:269-305 [Golubnitschaja O (Series Editor): Advances in Predictive, Preventive and Personalised Medicine, vol 1.].

16. Golubnitschaja O: Changing long-held beliefs is never easy: proposal for multimodal approaches in female healthcare-an integrative view. In Healthcare Overview: New Perspectives. Edited by Costigliola V. Dordrecht: Springer; 2012:251-268 [Golubnitschaja O (Series Editor): Advances in Predictive, Preventive and Personalised Medicine, vol 1.].

17. Golubnitschaja O, Costigliola V: General report \& recommendations in predictive, preventive and personalised medicine 2012: White Paper of the European Association for Predictive, Preventive and Personalised Medicine. EPMA J 2012, 3:14.

18. Mesle F: [Gender gap in life expectancy: the reasons for a reduction of female advantage]. Rev Epidemio/ Sante Publique 2004, 52:333-352.

19. Trovato F, Lalu NM: Contribution of cause-specific mortality to changing sex differences in life expectancy: seven nations case study. Soc Biol 1998, 45:1-20.

20. Trovato F, Lalu N: From divergence to convergence: the sex differential in life expectancy in Canada, 1971-2000. Can Rev Sociol Anthropol 2007, 44:101-122.

21. Trovato F, Heyen NB: A divergent pattern of the sex difference in life expectancy: Sweden and Japan, early 1970s-late 1990s. Soc Biol 2003, 50:238-258.

22. Crimmins EM, Hayward MD, Ueda H, Saito Y, Kim JK: Life with and without heart disease among women and men over 50. J Women Aging 2008, 20:5-19.

23. Whitlock G, Lewington S, Sherliker P, Clarke R, Emberson J, Halsey J, Qizilbash N, Collins R, Peto R: Body-mass index and cause-specific mortality in 900000 adults: collaborative analyses of 57 prospective studies. Lancet 2009, 373:1083-1096.

24. WHO: Global Health Observatory: 2010 [http://apps.who.int/ghodata]

25. Health Division OECD, OECD Health Division: OECD Health Data: 2012 [http://www.oecd.org/health/healthpoliciesanddata/oecdhealthdata2012.htm]

26. Preston $\mathrm{SH}$, Stokes $\mathrm{A}$ : Contribution of obesity to international differences in life expectancy. Am J Public Health 2011, 101:2137-2143.

27. Finkelstein EA, Brown DS, Wrage LA, Allaire BT, Hoerger TJ: Individual and aggregate years-of-life-lost associated with overweight and obesity. Obesity (Silver Spring) 2010, 18:333-339.

28. Flegal KM, Carroll MD, Ogden CL, Curtin LR: Prevalence and trends in obesity among US adults, 1999-2008. JAMA 2010, 303:235-241.

29. Peto R, Whitlock G, Jha P: Effects of obesity and smoking on U.S. life expectancy. N Engl J Med 2010, 362:855-856.

30. Walls HL, Backholer K, Proietto J, McNeil JJ: Obesity and trends in life expectancy. J Obes 2012, 2012:107989.

31. Reuser M, Bonneux LG, Willekens FJ: Smoking kills, obesity disables: a multistate approach of the US Health and Retirement Survey. Obesity (Silver Spring) 2009, 17:783-789.

32. Swinburn BA, Sacks G, Hall KD, McPherson K, Finegood DT, Moodie ML, Gortmaker SL: The global obesity pandemic: shaped by global drivers and local environments. Lancet 2011, 378:804-814. 
33. Ogden CL, Carroll MD, Curtin LR, McDowell MA, Tabak CJ, Flegal KM: Prevalence of overweight and obesity in the United States, 1999-2004. JAMA 2006, 295:1549-1555.

34. Chumlea WC, Guo SS, Kuczmarski RJ, Flegal KM, Johnson CL, Heymsfield SB, Lukaski HC, Friedl K, Hubbard VS: Body composition estimates from NHANES III bioelectrical impedance data. Int J Obes Relat Metab Disord 2002, 26:1596-1609.

35. Ruderman NB, Schneider SH, Berchtold P: The "metabolically-obese," normal-weight individual. Am J Clin Nutr 1981, 34:1617-1621.

36. O'Sullivan AJ: Does oestrogen allow women to store fat more efficiently? A biological advantage for fertility and gestation. Obes Rev 2009, 10:168-177.

37. Mittendorfer B, Patterson BW, Klein S: Effect of sex and obesity on basal VLDL-triacylglycerol kinetics. Am J Clin Nutr 2003, 77:573-579.

38. Mittendorfer B: Insulin resistance: sex matters. Curr Opin Clin Nutr Metab Care 2005, 8:367-372.

39. Mittendorfer B: Sexual dimorphism in human lipid metabolism. J Nutr 2005, 135:681-686.

40. Magkos F, Wang X, Mittendorfer B: Metabolic actions of insulin in men and women. Nutrition 2010, 26:686-693.

41. Medrikova D, Jilkova ZM, Bardova K, Janovska P, Rossmeisl M, Kopecky J: Sex differences during the course of diet-induced obesity in mice: adipose tissue expandability and glycemic control. Int J Obes (Lond) 2012 36:262-272

42. Samara A, Herbeth B, Aubert R, Berrahmoune H, Fumeron F, Siest G, Visvikis-Siest S: Sex-dependent associations of leptin with metabolic syndrome-related variables: the Stanislas study. Obesity (Silver Spring) 2010, 18:196-201.

43. Conus F, Allison DB, Rabasa-Lhoret R, St-Onge M, St-Pierre DH, TremblayLebeau A, Poeh/man ET: Metabolic and behavioral characteristics of metabolically obese but normal-weight women. J Clin Endocrinol Metab 2004, 89:5013-5020.

44. Dvorak RV, DeNino WF, Ades PA, Poehlman ET: Phenotypic characteristics associated with insulin resistance in metabolically obese but normalweight young women. Diabetes 1999, 48:2210-2214.

45. Katsuki A, Sumida Y, Urakawa H, Gabazza EC, Murashima S, Maruyama N, Morioka K, Nakatani K, Yano Y, Adachi Y: Increased visceral fat and serum levels of triglyceride are associated with insulin resistance in Japanese metabolically obese, normal weight subjects with normal glucose tolerance. Diabetes Care 2003, 26:2341-2344

46. Hyun YJ, Koh SJ, Chae JS, Kim JY, Kim OY, Lim HH, Jang Y, Park S, Ordovas $J M$, Lee $J H$ : Atherogenecity of LDL and unfavorable adipokine profile in metabolically obese, normal-weight woman. Obesity (Silver Spring) 2008, 16:784-789.

47. Wulan SN, Westerterp KR, Plasqui G: Ethnic differences in body composition and the associated metabolic profile: a comparative study between Asians and Caucasians. Maturitas 2010, 65:315-319.

48. De Lorenzo A, Bianchi A, Maroni P, lannarelli A, Di Daniele N, lacopino L, Di Renzo L: Adiposity rather than BMI determines metabolic risk. Int J Cardio/ 2011. doi:10.1016/j.jicard.2011.10.006

49. Ibanez L, Sebastiani G, Lopez-Bermejo A, Diaz M, Gomez-Roig MD, deZegher F: Gender specificity of body adiposity and circulating adiponectin, visfatin, insulin, and insulin growth factor-I at term birth: relation to prenatal growth. J Clin Endocrinol Metab 2008, 93:2774-2778.

50. He Q, Horlick M, Thornton J, Wang J, Pierson RN Jr, Heshka S, Gallagher D: Sex and race differences in fat distribution among Asian, AfricanAmerican, and Caucasian prepubertal children. J Clin Endocrinol Metab 2002, 87:2164-2170

51. Wang $Y$ : Is obesity associated with early sexual maturation? A comparison of the association in American boys versus girls. Pediatrics 2002, 110:903-910.

52. Davidsen L, Vistisen B, Astrup A: Impact of the menstrual cycle on determinants of energy balance: a putative role in weight loss attempts. Int J Obes (Lond) 2007, 31:1777-1785.

53. Steinbaum SR: The metabolic syndrome: an emerging health epidemic in women. Prog Cardiovasc Dis 2004, 46:321-336.

54. Faulds MH, Zhao C, Dahlman-Wright K, Gustafsson JA: The diversity of sex steroid action: regulation of metabolism by estrogen signaling. $J$ Endocrinol 2012, 212:3-12

55. Regitz-Zagrosek V, Lehmkuhl E, Mahmoodzadeh S: Gender aspects of the role of the metabolic syndrome as a risk factor for cardiovascular disease. Gend Med 2007, 4(Suppl B):S162-S177.
56. Senechal M, Arguin H, Bouchard DR, Carpentier AC, Ardilouze $J \mathrm{~L}$, Dionne IJ, Brochu M: Weight gain since menopause and its associations with weight loss maintenance in obese postmenopausal women. Clin Interv Aging 2011, 6:221-225.

57. Guo SS, Zeller C, Chumlea WC, Siervogel RM: Aging, body composition, and lifestyle: the Fels Longitudinal Study. Am J Clin Nutr 1999, 70:405-411.

58. Lewis CE, Smith DE, Wallace DD, Williams OD, Bild DE, Jacobs DR Jr: Sevenyear trends in body weight and associations with lifestyle and behavioral characteristics in black and white young adults: the CARDIA study. Am J Public Health 1997, 87:635-642.

59. Mann T, Tomiyama AJ, Westling E, Lew AM, Samuels B, Chatman J: Medicare's search for effective obesity treatments: diets are not the answer. Am Psychol 2007, 62:220-233.

60. Teixeira PJ, Going SB, Sardinha LB, Lohman TG: A review of psychosocial pre-treatment predictors of weight control. Obes Rev 2005, 6:43-65.

61. Mosca L, Benjamin EJ, Berra K, Bezanson JL, Dolor RJ, Lloyd-Jones DM, Newby LK, Pina IL, Roger VL, Shaw LJ, Zhao D, Beckie TM, Bushnell C, D'Armiento J, Kris-Etherton PM, Fang J, Ganiats TG, Gomes AS, Gracia CR, Haan CK, Jackson EA, Judelson DR, Kelepouris E, Lavie CJ, Moore A, Nussmeier NA, Ofili E, Oparil S, Ouyang P, Pinn WW, et al: Effectivenessbased guidelines for the prevention of cardiovascular disease in women-2011 update: a guideline from the American Heart Association. J Am Coll Cardiol 2011, 57:1404-1423.

62. Retnakaran R: Glucose tolerance status in pregnancy: a window to the future risk of diabetes and cardiovascular disease in young women. Curr Diabetes Rev 2009, 5:239-244.

63. Rogers RG, Everett BG, Onge JM, Krueger PM: Social, behavioral, and biological factors, and sex differences in mortality. Demography 2010, 47:555-578

64. McLaren L: Socioeconomic status and obesity. Epidemiol Rev 2007, 29:29-48.

65. Kurth T, Moore SC, Gaziano JM, Kase CS, Stampfer MJ, Berger K, Buring JE: Healthy lifestyle and the risk of stroke in women. Arch Intern Med 2006, 166:1403-1409.

66. Stampfer MJ, Hu FB, Manson JE, Rimm EB, Willett WC: Primary prevention of coronary heart disease in women through diet and lifestyle. $N$ Engl $J$ Med 2000, 343:16-22.

67. McCullough ML, Patel AV, Kushi LH, Patel R, Willett WC, Doyle C, Thun MJ, Gapstur SM: Following cancer prevention guidelines reduces risk of cancer, cardiovascular disease, and all-cause mortality. Cancer Epidemiol Biomarkers Prev 2011, 20:1089-1097.

68. Ronco AL, DeStefani E, Stoll M: Hormonal and metabolic modulation through nutrition: towards a primary prevention of breast cancer. Breast 2010, 19:322-332.

69. Romaguera D, Angquist L, Du H, Jakobsen MU, Forouhi NG, Halkjaer J, Feskens EJ, van der A DL, Masala G, Steffen A, Palli D, Wareham NJ, Overvad K, Tjønneland A, Boeing H, Riboli E, Sørensen Tl: Food composition of the diet in relation to changes in waist circumference adjusted for body mass index. PLoS One 2011, 6:e23384.

70. Allen NE, Beral V, Casabonne D, Kan SW, Reeves GK, Brown A, Green J: Moderate alcohol intake and cancer incidence in women. $J$ Natl Cancer Inst 2009, 101:296-305

71. Boffetta P, Hashibe M: Alcohol and cancer. Lancet Oncol 2006, 7:149-156.

72. Hong J, Holcomb VB, Dang F, Porampornpilas K, Nunez NP: Alcohol consumption, obesity, estrogen treatment and breast cancer. Anticancer Res 2010, 30:1-8.

73. Shai I, Wainstein J, Harman-Boehm I, Raz I, Fraser D, Rudich A, Stampfer MJ: Glycemic effects of moderate alcohol intake among patients with type 2 diabetes: a multicenter, randomized, clinical intervention trial. Diabetes Care 2007, 30:3011-3016

74. Chen WY, Rosner B, Hankinson SE, Colditz GA, Willett WC: Moderate alcohol consumption during adult life, drinking patterns, and breast cancer risk. JAMA 2011, 306:1884-1890.

75. Latino-Martel P, Arwidson P, Ancellin R, Druesne-Pecollo N, Hercberg S, Le Quellec-Nathan M, Le-Luong T, Maraninchi D: Alcohol consumption and cancer risk: revisiting guidelines for sensible drinking. CMAJ 2011, 183:1861-1865.

76. Trovato GM: Behavior, nutrition and lifestyle in a comprehensive health and disease paradigm: skills and knowledge for a predictive, preventive and personalized medicine. EPMA J 2012, 3:8

77. Wing RR, Jeffery RW: Effect of modest weight loss on changes in cardiovascular risk factors: are there differences between men and 
women or between weight loss and maintenance? Int J Obes Relat Metab Disord 1995, 19:67-73.

78. Janssen I, Ross R: Effects of sex on the change in visceral, subcutaneous adipose tissue and skeletal muscle in response to weight loss. Int J Obes Relat Metab Disord 1999, 23:1035-1046.

79. Rice B, Janssen I, Hudson R, Ross R: Effects of aerobic or resistance exercise and/or diet on glucose tolerance and plasma insulin levels in obese men. Diabetes Care 1999, 22:684-691.

80. Janssen I, Fortier A, Hudson R, Ross R: Effects of an energy-restrictive diet with or without exercise on abdominal fat, intermuscular fat, and metabolic risk factors in obese women. Diabetes Care 2002, 25:431-438.

81. Ross R, Janssen I, Dawson J, Kungl AM, Kuk JL, Wong SL, Nguyen-Duy TB, Lee S, Kilpatrick K, Hudson R: Exercise-induced reduction in obesity and insulin resistance in women: a randomized controlled trial. Obes Res 2004, 12:789-798.

82. Wirth A, Steinmetz B: Gender differences in changes in subcutaneous and intra-abdominal fat during weight reduction: an ultrasound study. Obes Res 1998, 6:393-399.

83. Berentzen TL, Jakobsen MU, Halkjaer J, Tjonneland A, Sorensen TI, Overvad $\mathrm{K}$ : Changes in waist circumference and the incidence of diabetes in middle-aged men and women. PLoS One 2011, 6:e23104.

84. Sobngwi E, Mbanya JC, Unwin NC, Porcher R, Kengne AP, Fezeu L, Minkoulou EM, Tournoux C, Gautier JF, Aspray TJ, Alberti K: Exposure over the life course to an urban environment and its relation with obesity, diabetes, and hypertension in rural and urban Cameroon. Int J Epidemiol 2004, 33:769-776.

85. Li Z, Otvos JD, Lamon-Fava S, Carrasco WW, Lichtenstein AH, McNamara JR, Ordovas JM, Schaefer E: Men and women differ in lipoprotein response to dietary saturated fat and cholesterol restriction. J Nutr 2003, 133:3428-3433.

86. LaRosa JC: Lipids and cardiovascular disease: do the findings and therapy apply equally to men and women? Womens Health Issues 1992, 2:102-111.

87. Kuller LH, Simkin-Silverman LR, Wing RR, Meilahn EN, Ives DG: Women's Healthy Lifestyle Project: a randomized clinical trial: results at 54 months. Circulation 2001, 103:32-37.

88. Sieri S, Krogh V, Berrino F, Evangelista A, Agnoli C, Brighenti F, Pellegrini N, Palli D, Masala G, Sacerdote C, Veglia F, Tumino R, Frasca G, Grioni S, Pala V Mattiello A, Chiodini P, Panico S: Dietary glycemic load and index and risk of coronary heart disease in a large italian cohort: the EPICOR study. Arch Intern Med 2010, 170:640-647.

89. Howard BV, Van HL, Hsia J, Manson JE, Stefanick ML, Wassertheil-Smoller S, Kuller LH, LaCroix AZ, Langer RD, Lasser NL, Lewis CE, Limacher MC, Margolis KL, Mysiw WJ, Ockene JK, Parker LM, Perri MG, Phillips L, Prentice RL, Robbins J, Rossouw JE, Sarto GE, Schatz IJ, Snetselaar LG, Stevens VJ, Tinker LF, Trevisan M, Vitolins MZ, Anderson GL, Assaf AR, et al: Low-fat dietary pattern and risk of cardiovascular disease: the Women's Health Initiative Randomized Controlled Dietary Modification Trial. JAMA 2006, 295:655-666.

90. Lapointe A, Couillard C, Lemieux S: Effects of dietary factors on oxidation of low-density lipoprotein particles. J Nutr Biochem 2006, 17:645-658.

91. Sies $H$, Stahl W, Sevanian A: Nutritional, dietary and postprandial oxidative stress. J Nutr 2005, 135:969-972.

92. Burdge GC, Calder PC: Conversion of alpha-linolenic acid to longer-chain polyunsaturated fatty acids in human adults. Reprod Nutr Dev 2005, 45:581-597.

93. Childs CE, Romeu-Nadal M, Burdge GC, Calder PC: Gender differences in the n-3 fatty acid content of tissues. Proc Nutr Soc 2008, 67:19-27.

94. de Catalfo GE H, de Gomez Dumm I: Influence of testosterone on polyunsaturated fatty acid biosynthesis in Sertoli cells in culture. Cell Biochem Funct 2005, 23:175-180.

95. Marra CA, de Alaniz MJ: Influence of testosterone administration on the biosynthesis of unsaturated fatty acids in male and female rats. Lipids 1989, 24:1014-1019.

96. Bolton-Smith C, Woodward M, Tavendale R: Evidence for age-related differences in the fatty acid composition of human adipose tissue, independent of diet. Eur J Clin Nutr 1997, 51:619-624.

97. Warensjo E, Riserus U, Gustafsson IB, Mohsen R, Cederholm T, Vessby B: Effects of saturated and unsaturated fatty acids on estimated desaturase activities during a controlled dietary intervention. Nutr Metab Cardiovasc Dis 2008, 18:683-690.

98. Brenner RR, Bernasconi AM, Gonzalez MS, Rimoldi OJ: Dietary cholesterol modulates delta 6 and delta9 desaturase mRNAs and enzymatic activity in rats fed a low-eFA diet. Lipids 2002, 37:375-383.
99. Shapira N: Women's higher risk with n-6 PUFA vs. men's relative advantage: an 'N-6 Gender Paradox' hypothesis. Isr Med Assoc J 2012, 14:435-441.

100. Dubnov G, Berry EM: Omega-6/omega-3 fatty acid ratio: the Israel paradox. World Rev Nutr Diet 2003, 92:81-91.

101. Yam D, Eliraz A, Berry EM: Diet and disease-the Israeli paradox: possible dangers of a high omega- 6 polyunsaturated fatty acid diet. Isr J Med SCi 1996, 32:1134-1143.

102. Dahm CC, Gorst-Rasmussen A, Jakobsen MU, Schmidt EB, Tjonneland A, Sorensen TI, Overvad K: Adipose tissue fatty acid patterns and changes in anthropometry: a cohort study. PLOS One 2011, 6:e22587.

103. Lofgren IE, Herron KL, West KL, Zern TL, Patalay M, Koo SI, Fernandez ML. Carbohydrate intake is correlated with biomarkers for coronary heart disease in a population of overweight premenopausal women. $J$ Nutr Biochem 2005, 16:245-250

104. Mozaffarian D, Rimm EB, Herrington DM: Dietary fats, carbohydrate, and progression of coronary atherosclerosis in postmenopausal women. Am J Clin Nutr 2004, 80:1175-1184.

105. Beulens JW, de Bruijne LM, Stolk RP, Peeters PH, Bots ML, Grobbee DE, van der Schouw YT: High dietary glycemic load and glycemic index increase risk of cardiovascular disease among middle-aged women: a populationbased follow-up study. J Am Coll Cardiol 2007, 50:14-21.

106. Barclay AW, Petocz P, Millan-Price J, Flood VM, Prvan T, Mitchell P, BrandMiller JC: Glycemic index, glycemic load, and chronic disease risk-a meta-analysis of observational studies. Am J Clin Nutr 2008, 87:627-637.

107. van Woudenbergh GJ, Kuijsten A, Sijbrands EJ, Hofman A, Witteman JC, Feskens EJ: Glycemic index and glycemic load and their association with C-reactive protein and incident type 2 diabetes. J Nutr Metab 2011, 2011:623076.

108. Liu S, Manson JE, Buring JE, Stampfer MJ, Willett WC, Ridker PM: Relation between a diet with a high glycemic load and plasma concentrations of high-sensitivity C-reactive protein in middle-aged women. Am J Clin Nutr 2002, 75:492-498.

109. Wong MH, Holst C, Astrup A, Handjieva-Darlenska T, Jebb SA, Kafatos A, Kunesova M, Larsen TM, Martinez JA, Pfeiffer AF, van Baak MA, Saris WHM, McNicholas PD, Mutch DM, DiOGenes: Caloric restriction induces changes in insulin and body weight measurements that are inversely associated with subsequent weight regain. PLoS One 2012, 7:e42858.

110. Josse AR, Atkinson SA, Tarnopolsky MA, Phillips SM: Increased consumption of dairy foods and protein during diet- and exercise-induced weight loss promotes fat mass loss and lean mass gain in overweight and obese premenopausal women. J Nutr 2011, 141:1626-1634.

111. Parker B, Noakes M, Luscombe N, Clifton P: Effect of a high-protein, highmonounsaturated fat weight loss diet on glycemic control and lipid levels in type 2 diabetes. Diabetes Care 2002, 25:425-430.

112. De Lorenzo MS, Baljinnyam E, Vatner DE, Abarzua P, Vatner SF, Rabson AB: Caloric restriction reduces growth of mammary tumors and metastases. Carcinogenesis 2011, 32:1381-1387.

113. Sorensen LB, Soe M, Halkier KH, Stigsby B, Astrup A: Effects of increased dietary protein-to-carbohydrate ratios in women with polycystic ovary syndrome. Am J Clin Nutr 2012, 95:39-48.

114. Meckling KA, Sherfey R: A randomized trial of a hypocaloric high-protein diet, with and without exercise, on weight loss, fitness, and markers of the Metabolic Syndrome in overweight and obese women. Appl Physiol Nutr Metab 2007, 32:743-752

115. Malik VS, Sun Q, van Dam RM, Rimm EB, Willett WC, Rosner B, Hu FB: Adolescent dairy product consumption and risk of type 2 diabetes in middle-aged women. Am J Clin Nutr 2011, 94:854-861.

116. Yates T, Khunti K, Wilmot EG, Brady E, Webb D, Srinivasan B, Henson J, Talbot D, Davies MJ: Self-reported sitting time and markers of inflammation, insulin resistance, and adiposity. Am J Prev Med 2012, 42:1-7

117. Woolf K, Reese CE, Mason MP, Beaird LC, Tudor-Locke C, Vaughan LA: Physical activity is associated with risk factors for chronic disease across adult women's life cycle. J Am Diet Assoc 2008, 108:948-959.

118. Tarnopolsky MA, Atkinson SA, Phillips SM, MacDougall JD: Carbohydrate loading and metabolism during exercise in men and women. $J$ Appl Physiol 1995, 78:1360-1368.

119. Ekelund U, Besson H, Luan J, May AM, Sharp SJ, Brage S, Travier N, Agudo A, Slimani N, Rinaldi S, Jenab M, Norat T, Mouw T, Rohrmann S, Kaaks R, Bergmann MM, Boeing H, Clavel-Chapelon F, Boutron-Ruault MC, Overvad K, 
Jakobsen MU, Johnsen NF, Halkjaer J, Gonzalez CA, Rodriguez L, Sanchez MJ, Arriola L, Barricarte A, Navarro C, Key TJ, et al: Physical activity and gain in abdominal adiposity and body weight: prospective cohort study in 288,498 men and women. Am J Clin Nutr 2011, 93:826-835.

120. Holick CN, Newcomb PA, Trentham-Dietz A, Titus-Ernstoff L, Bersch AJ, Stampfer MJ, Baron JA, Egan KM, Willett WC: Physical activity and survival after diagnosis of invasive breast cancer. Cancer Epidemiol Biomarkers Prev 2008, 17:379-386

121. American Cancer Society: Limit Alcohol to Lower Cancer Risk. Atlanta: American Cancer Society; 2011.

doi:10.1186/1878-5085-4-1

Cite this article as: Shapira: Women's higher health risks in the obesogenic environment: a gender nutrition approach to metabolic dimorphism with predictive, preventive, and personalised medicine. The EPMA Journal 2013 4:1.

\section{Submit your next manuscript to BioMed Central and take full advantage of:}

- Convenient online submission

- Thorough peer review

- No space constraints or color figure charges

- Immediate publication on acceptance

- Inclusion in PubMed, CAS, Scopus and Google Scholar

- Research which is freely available for redistribution 